\title{
A graphene film interlayer for enhanced electrical conductivity in a carbon-fibre/ PEEK composite
}

\author{
Christopher Leow $^{1 *} \mathbb{D}$, Peter B. Kreider ${ }^{1}$, Christian Notthoff ${ }^{2}$, Patrick Kluth², Antonio Tricoli ${ }^{3}$ and Paul Compston ${ }^{1}$
}

\begin{abstract}
Carbon-fibre reinforced composites are seeing increased deployment, especially in the aerospace industry, and the next-generation of these materials will need to meet demanding performance requirements beyond just specific strength. The incorporation of nanomaterials such as graphene into composites has great potential for enhancing electrical, thermal, and mechanical properties, which could then enable new capabilities such as built-in lightning strike protection and electromagnetic shielding. One major challenge is successful integration of nanomaterials into the composite during the manufacturing process especially for thermoplastic based composites. This work explores the spray deposition of exfoliated graphene in liquid suspensions for the nano-enhancement of electrical properties in carbon-fibre reinforced polyether ether keytone (PEEK) composites. Developed thin films were smooth with RMS roughness of $1.06 \mu \mathrm{m}$ on Si substrates and RMS roughness of $1.27 \mu \mathrm{m}$ on CF-PEEK tapes. The addition of $1.3 \mathrm{wt} \%$ graphene into the interlayers of CF-PEEK composites resulted in bulk electrical conductivity enhancement both in plane and through thickness of $\sim 1100 \%$ and $67.5 \%$ respectively. This approach allows for pre-consolidation introduction of high-performance nanomaterials directly to thermoplastic prepregs which could open simple pathways for the in-situ manufacturing of carbon-fibre reinforced polymer nanocomposites.
\end{abstract}

Keywords: Nanocomposite, Nanomaterials, Thermoplastics, Graphene, Spray-deposition

\section{Introduction}

Electrical and thermal conductivity enhancement of carbon fibre reinforced polymer composites (CFRPs) could extend functional capabilities into areas such as lightning strike protection $[1,2]$, electrostatic discharge $[3,4]$ and electromagnetic shielding [5-7]. Significant thermal and electrical conductivity advancements have been achieved with the addition of nanomaterials into fibre reinforced polymer composites [8-10]. The high strength, chemically-resistant, and temperature-tolerant properties of polyether ether ketone (PEEK) [11] classify it as a high-performance polymer matrix material suited to aerospace and automotive industries [12]. Due to the

\footnotetext{
* Correspondence: christopher.leow@anu.edu.au

'ARC Training Centre for Automated Manufacture of Advanced Composites, Research School of Electrical, Energy and Materials Engineering, Australian

National University, Canberra, ACT 2601, Australia

Full list of author information is available at the end of the article
}

insulative properties of PEEK [13] lightning-strike protection, electrostatic dissipation and thermal management functions remain out of reach without further modification. The addition of enhancing nanomaterials to CFRPs has shown to be an effective approach for composite property modification [8-10].

Several nanomaterials have been investigated as inclusions into fibre reinforced composite systems to electrically enhance the insulating nature of polymer matrix systems including carbon black $[14,15]$, carbon nanotubes (CNTs) [16, 17], graphene nanoplatelets (GNPs) $[7,18]$, graphene oxide $[19,20]$, silver nanowires [21] and combinations of nanomaterial additions [22, 23]. The outstanding theoretical properties of graphene such as impressive tensile strength $(\sim 1 \mathrm{TPa})$ [24], high specific surface area $\left(2630 \mathrm{~m}^{2} \mathrm{~g}^{-1}\right)$ [25], excellent thermal conductivity $\left(5300 \mathrm{Wm}^{-1} \mathrm{~K}^{-1}\right)$ [26], and extremely high 
electrical conductivity $\left(2000 \mathrm{Scm}^{-1}\right)$ [27] make it a strong nanomaterial candidate for enhancing CFRPs. Carbonaceous nanomaterials are also galvanically compatible with carbon fibres, unlike metallic nanoadditions [28].

Liquid phase exfoliation (LPE) is a scalable method that can produce high quality, high purity graphene at relatively low cost compared to mechanical exfoliation, chemical vapour deposition, synthesis on $\mathrm{SiC}$, bottom up synthesis, and the reduction of graphene oxide (GO) methods [27]. Many different combinations of surfactants, solvents and exfoliation conditions have been studied in the past to achieve high concentration pristine graphene [29] and GO [30] suspensions.

Interlaminar modifications have the potential to integrate with existing prepreg composite production methodologies in a scalable way without major disruptions. Direct addition of nanomaterials onto reinforcing fibres can reduce mechanical properties by altering the fracture behaviour in the interphase region [31]. Enhancement of the matrix phase can lead to significant increases in viscosity causing restricted rein flow, uneven nanomaterial distribution, voids and dry spots, which can severely limit the possible composite manufacturing techniques that can be employed [32].

Multi-walled CNT buckypaper interleaves $0.15 \mathrm{~mm}$ thick have been added into epoxy CFRP resulting in through-thickness conductivity values of $0.52 \mathrm{Scm}^{-1}$ [33]. Graphene films of approximately $25-140 \mu \mathrm{m}$ were sandwiched between prepreg carbon fibre epoxy composite yielding electrical conductivities of $1300 \mathrm{Scm}^{-1}$ and thermal conductivities up to $425 \mathrm{Wm}^{-1} \mathrm{~K}^{-1}$ [34]. Enhancements to interlaminar shear strength properties have also been observed through interlayer additions [35], however decreased flexural properties and delamination due to poor adhesion between the nanomaterials and the fibre reinforced composite have also been reported after interlayer nanoadditions [33, 34].

Spray-deposition methods onto plies have been used to functionalise composites while also enabling the use of LPE nanomaterials. Zhang et al. spray-deposited a CNT/ methanol formulation onto CF epoxy prepreg tapes to enhance fracture toughness for integrated sensing capabilities [35]. Similarly, Li et al also used a spray system to deposit 4.5-5 $\mu \mathrm{m}$ CNT/GNP mixtures onto CF epoxy prepreg tapes for enhanced electrical $\left(3.4 \times 10^{-4} \Omega \mathrm{sq}^{-1}\right)$ and thermal conductivity $\left(1500 \mathrm{Wm}^{-1} \mathrm{~K}^{-1}\right)$ [36].

In this work electrical property enhancement of carbon fibre PEEK prepreg tape through interlayer additions is investigated The aqueous graphene nanosuspension synthesised using LPE methods was aerosolised and sprayed to generate graphene thin films on both silicon wafers and CF-PEEK prepreg tapes. The wetting behaviour of the aqueous suspensions on both substrates was also was quantified. The resultant graphene thin films were characterised for quality using optical microscopy, white light interferometry (WLI), scanning electron microscopy (SEM), and Raman spectroscopy. The graphene coated CF-PEEK tapes were then consolidated to create interlayer enhanced thermoplastic composites for further study via SEM, Raman spectroscopy, conductive-atomic force microscopy (C-AFM) and electrical characterisation.

\section{Experimental Materials}

The aqueous graphene suspension (from FlexeGRAPH) was synthesised in an ultrasonic flow cell via the liquidphase exfoliation of graphite using a pluronic non-ionic surfactant (F108, Sigma-Aldrich). The surfactant was added continuously to achieve high graphene concentrations of $\sim 1.5 \mathrm{wt} \%$ [29]. AS-4 carbon fibre (CF) reinforced polyether ether ketone (PEEK) unidirectional tapes (Toray Cetex, fibre volume fraction 59\%) and boron-doped silicon wafers (single side polished, boron concentration of $1.4 \times 10^{19} \mathrm{~cm}^{-3}$ ) were used as substrates for the spray deposition process.

\section{Sample preparation}

Spray deposition was conducted using flat fan air atomising nozzle (SUE15, Xinhou Industrial Co. Ltd), paired with an NE-300 syringe pump (New Era Pump Systems Inc.) and $30 \mathrm{~mm}$ (dia.) syringe (Henke Sass Wolf). The suspension was aerosolised with air pressure at $1 \mathrm{bar}$ and a liquid graphene suspension feed rate of 5 $\mathrm{mLmin}^{-1}$. The substrate was spray-coated for $30 \mathrm{~s}$ at a distance of $300 \mathrm{~mm}$ (Fig. 1) followed by a drying step at $50^{\circ} \mathrm{C}$ on a hot plate. This process was repeated five times for each individual CF-PEEK ply and Si wafer substrates.

Nine CF-PEEK plies $(40 \mathrm{~mm} \times 90 \mathrm{~mm})$ were laid up in $\left[(0,90)_{4}, \overline{0}\right]$ orientation, in a picture frame mould to generate a simple consolidated control part using a hot press procedure adapted from Cogswell [37]. The picture frame mould was heated in a hot press (PW220C$\mathrm{X} 4 \mathrm{~A}$, Phi Hydraulics) at $385^{\circ} \mathrm{C}$ for 9 minutes at contact pressure then $1 \mathrm{MPa}$ consolidated pressure applied for 9 minutes ( 1 min per ply) before water-cooling with pressure maintained at a rate of $\sim 40^{\circ} \mathrm{C} / \mathrm{min}$ to below $\mathrm{T}_{\mathrm{g}}$ $\left(140^{\circ} \mathrm{C}\right)$. This layup and consolidation procedure was repeated with graphene-enhanced CF-PEEK tapes, where the surfaces of the bottom eight plies were spray-coated with graphene as outlined above to achieve a graphene thin film $(38.4 \pm 3.2 \mathrm{mg})$ on each ply and $1.3 \mathrm{wt} \%$ graphene total (Fig. 1b).

Consolidated CF-PEEK control and graphene enhanced composites required further processing for cross sectional imaging and direct analysis of the interlaminar regions. The consolidated parts were cut on a bandsaw 


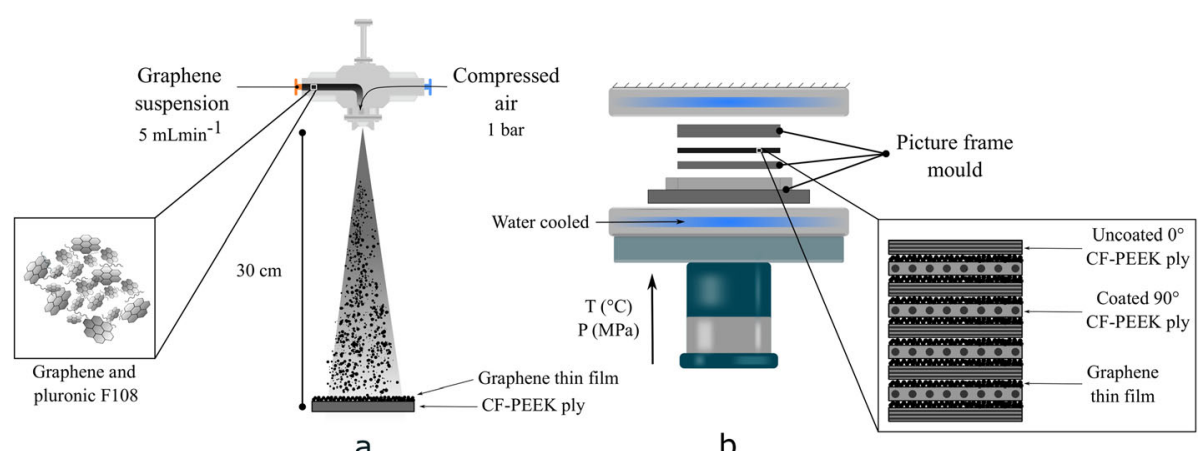

b

Fig. 1 a Schematic of the system used to aerosolise and deposit graphene suspension onto substrates with graphical representation of graphene and pluronic F108 suspension inset. $\mathbf{b}$ Hot press system and picture frame mould configuration to consolidate and cool composite samples with graphene enhanced layup inset

into $10 \mathrm{~mm} \times 10 \mathrm{~mm}$ coupons and then cast on-end in an epoxy resin (EpoFix) using a resin:hardener ratio of 5 : 1. The sample coupons in liquid EpoFix resin were then de-gassed under vacuum for approximately 1 minute to remove bubbles and ensure even distribution of resin before curing for $24 \mathrm{~h}$. Samples were sliced into $1.5 \mathrm{~mm}$ thick disks with an Allied Techcut 4 (Allied High Tech Productions Inc.) with a diamond metal bonded wafering blade with gravity pressure applied. The cut disks were then mounted onto metallic holders using carbon tape and polished using an Allied MetPrep3 (Allied High Tech Productions Inc.) grinder/polisher sample preparation system with associated polishing pads and diamond suspension polishing solutions. The samples were polished using a clockwise platen rotation speed of 200 $\mathrm{rpm}$ and a sample head rotation speed of $150 \mathrm{rpm}$ counterclockwise with $17 \mathrm{~N}$ applied force for 1 minute with the sequential pre-polishing steps: P-400, P-1200 and P$2400 \mathrm{SiC}$ polishing paper (FEPA grit sizes). After the $\mathrm{SiC}$ prepolish, polishing steps were conducted for $2 \mathrm{~min}$ for C-AFM and for $4 \mathrm{~min}$ for SEM. Gold label woven nylon polishing pads were magnetically mounted onto the platen and sequentially polished with Allied High Tech green lube and $6 \mu \mathrm{m}$ and then $3 \mu \mathrm{m}$ polycrystalline diamond glycol-based suspension. Final polishing was conducted with white label woven low-nap silk and polished using a mix of green lube and $1 \mu \mathrm{m}$ polycrystalline diamond glycol-based suspension. Polished surfaces were cleaned with soap then dried with compressed air between grit changes. The C-AFM cross sectional disks were mounted onto $\varnothing 10 \mathrm{~mm}$ round metallic disks using silver paste to create a conductive and physical contact. The SEM cross sectional disks were sputter coated with a $15 \mathrm{~nm}$ layer of carbon to prevent surface charging.

A solid disc was created directly from graphene suspension to serve as an analogue to the spray-deposited films for electrical conductivity properties independent of spray deposition and consolidation effects. The graphene suspension $(50 \mathrm{~mL})$ was vacuum filtered through a $\varnothing 90 \mathrm{~mm} 0.2 \mu \mathrm{m}$ cellulose based micro filtration membrane for $24 \mathrm{~h}$ to generate a graphene-based solid. The resulting puck was placed in a drying oven for $24 \mathrm{~h}$ and a solid disk $0.26 \mathrm{~mm}$ thick was created.

\section{Characterisation}

Measurements of diluted graphene suspension were taken from 200 to $1100 \mathrm{~nm}$ on a Cary 60 UV-Vis Spectrophotometer to gain absorbance values and concentration (C) calculated using Lambert-Beer law (Eq. 1) [38]. Extinction coefficients $(\alpha)$ used to calculate concentrations have ranged from 5422 to $1293 \mathrm{Lg}^{-1} \mathrm{~m}^{-1}$ [39-41]. An extinction coefficient of $5422 \mathrm{mLmg}^{-1} \mathrm{~m}^{-1}$ was selected from Chabot et al. [39] as similar methods to create few-layer graphene aqueous suspension were employed. The resultant calculated concentration was $0.0013 \mathrm{mgmL}^{-1}$.

$$
\mathrm{A}=\alpha \mathrm{LC}
$$

Contact angle measurements were conducted with water and graphene suspension on $\mathrm{Si}$, CF-PEEK, and graphene coated CF-PEEK and Si substrates. A $250 \mu \mathrm{L}$ droplet of water or graphene suspension was dispensed and imaged using a Phoenix MT Touch contact angle Analyser (Surface Electro Optics). Images were captured with $2^{\circ}$ camera tilt relative to the sample stage and post processed in ImageJ using the DropSnake plugin [42].

Optical microscopy was conducted as a qualitative macroscopic validation method of thin film quality using a Nikon Eclipse E200 microscope captured on a DS-Vi1 microscope camera (Nikon). Surface topography and roughness measurements were conducted on VEECO Wyko NT9100 Optical Profiling System using Vertical Scanning Interferometry (VSI) techniques at $\times 1.0$ Field of View with full resolution at an objective of $\times 5$, or $\times$ 20. Five scans were taken at different locations on the 
sample to gain an average absolute and root-meansquare (RMS) roughness measurement. Zeiss UltraPlus analytical field emission SEM with an in-lens secondary electron (SE) detector was used to study samples at a working distance of $3.4 \mathrm{~mm}$ with $3 \mathrm{kV}$ accelerating voltage. ImageJ was used to measure flake sizes of the thin film deposited onto Si substrates.

A Renishaw inVia confocal Raman microscope was used at a magnification of $\times 50$ to chemically characterise graphene quality. Samples were exposed to a $532 \mathrm{~nm}$ wavelength laser at about $3 \mathrm{~mW}$ power with use of a $2400 \mathrm{~mm}^{-1}$ grating to isolate the signal and measurements were integrated over a period of $10 \mathrm{~s}$ with $10 \mathrm{ac}-$ cumulations to reduce signal to noise ratios. A Signatone 4-point probe standard SP4 head with Osmium probe spacing (s) of $1.57 \mathrm{~mm}$ (62 mil.) $85 \mathrm{~g}$ spring pressure and $0.04 \mathrm{~mm}$ (1.6 mil.) radius was used in conjunction with a Keithley 2400 sourcemeter to measure thin film electrical conductivity. Current sweep was conducted from $-1 \mathrm{~A}$ to $1 \mathrm{~A}$ in ten linear increments and voltage measured. A correction factor was applied to the results (Eq. 2) to attain sheet resistivity $(\Omega / \mathrm{sq})$ and multiplied by the thickness ( $\mathrm{t}$ ) of the film to gain resistivity $(\rho)$ [43]. The reciprocal of resistivity is conductivity (б) (Eq. 3).

$$
\mathrm{R}_{\mathrm{s}}=\rho / \mathrm{t}=45.3 \mathrm{~V} / \mathrm{I}
$$

For $\mathrm{t} / \mathrm{s} \leq 0.5$

$$
\sigma=1 / \rho
$$

The interlayer regions of control and graphene enhanced CF-PEEK composites were mapped using the Dimension Icon Atomic Force Microscopy (Bruker) with Platinum-Iridium tips. AFM and C-AFM measurements were conducted at ambient conditions using SCM-PICV2 (Bruker) probes operated with a spring constant of $0.1 \mathrm{~N} / \mathrm{m}$. Current mapping of an area of $10 \mu \mathrm{m}^{2}$ was conducted in contact mode with a $0.6 \mathrm{~V}$ deflection set point maintained with a $1 \mathrm{~V}$ bias applied to the cantilever. Mean grey average optical density measurements of the C-AFM maps were obtained using ImageJ (calibrated with a Kodak No. 3 step tablet [44]), where pixel colours ranging from black to white $(0-255)$ were indexed to the lowest (black) and highest (white) current measured, respecitvely. In plane and through thickness electrical conductivity measurements were taken using the two-point probe method with a digital multimeter (DigiTech QM1551).

\section{Results and discussion}

The quality and uniformity of spray-deposited thin films using aqueous nanosuspensions (as shown in Fig. 1a) can be affected by the wettability of the liquid on the solid substrate. Contact angle measurements were conducted to understand wetting behaviour of the suspension on substrates as a proxy for nanomaterial distribution in the thin film (Fig. 2). Water and graphene suspension contact angles measured on CF-PEEK exhibits highly wetting behaviour with an angle of and $17^{\circ}$ and $13^{\circ}$ respectively (Fig. 2a). For comparison, the water and graphene suspension contact angles on $\mathrm{Si}$ were measured at $28^{\circ}$ and $10^{\circ}$ respectively. Graphene coated CFPEEK samples continue to exhibit hydrophilic behaviour with contact angle measurements of $28^{\circ}$ (Fig. 2b) and $25^{\circ}$ with graphene suspension and water respectively. Graphene coated Si samples exhibited the least wetting behaviour of all the samples with of $40^{\circ}$ and $45^{\circ}$ contact angle measurements with graphene and water respectively. The highly wetting behaviour of the aqueous graphene suspension on the composite substrates combined with aerosolisation techniques instils confidence in the development of equally distributed nanomaterial thin films.

The spray-deposited graphene thin films on silicon and CF-PEEK substrates are shown in Fig. 3. A microscopic image of the smooth silicon wafer (Fig. 3a) was measured to have an average roughness of $282 \pm 2 \mathrm{~nm}$ and root mean square (RMS) roughness of $408 \pm 2 \mathrm{~nm}$ (Fig. 3b) using WLI. The graphene thin films deposited on the silicon wafer are uniform and smooth (Fig. 3c) with pinhole defects (up to $\varnothing 60 \mu \mathrm{m}$ ) and ridge-like drying patterns (approximately $15 \mu \mathrm{m}$ deep) from the spray process resulting in a peak-to-trough average of $8.4 \pm 0.14 \mu \mathrm{m}$ and RMS roughness of $1.06 \pm 0.19 \mu \mathrm{m}$ (Fig. 3d). The size of the pinhole defects and drying patterns on $\mathrm{Si}$ were on the same scale as the intrinsic surface features of CF-PEEK prepreg tapes with measured average roughness of $2.29 \pm 0.24 \mu \mathrm{m}$ and RMS roughness of $2.95 \pm 0.30 \mu \mathrm{m}$ (Fig. 3f). The resultant impact of these defects in the interlayer regions post-consolidation are likely inconsequential but may result in localised graphene poor regions. The deposition of a graphene thin film on CF-PEEK resulted in a smoother surface with less defined fibre topography on the ply visualised in Fig. 3g. The resultant roughness with the thin film has reduced to an average of $900 \pm 430 \mathrm{~nm}$ and RMS roughness of $1.27 \pm 0.52 \mu \mathrm{m}$ (Fig. $3 \mathrm{~h}$ ). The thin film appears to have covered the troughs between fibres creating a flat uniform coating.

Visual and chemical characterisation methods of the thin film were employed to validate quality of the graphene suspension on the nanoscale on Si and CF-PEEK substrates (Fig. 4). The nanographitic flakes seen in Fig. 4a had an average size of $413 \mathrm{~nm} \pm 61 \mathrm{~nm}$. The same nanocarbons can be seen on the CF-PEEK substrates in Fig. $4 \mathrm{~b}$ but are less obviously differentiable from one another; the average flake sizes were assumed to be the 


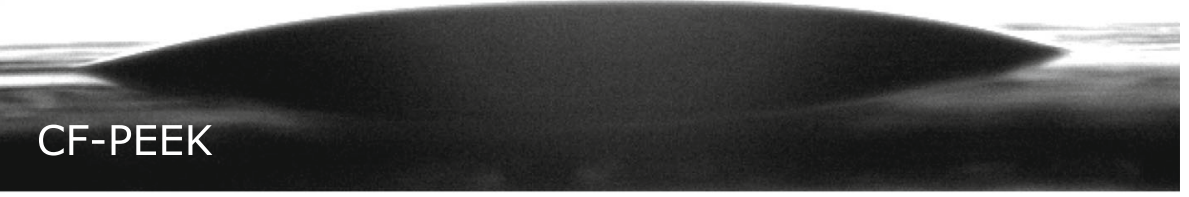

b $28^{\circ}$

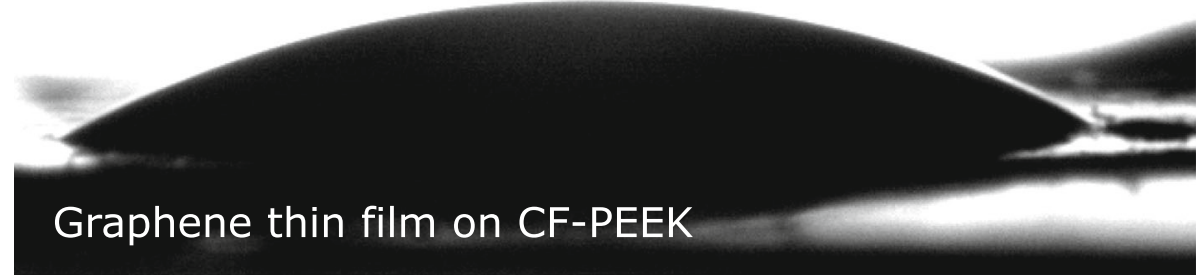

Fig. 2 Graphene suspension contact angle measurements on (a) CF-PEEK control ply and (b) CF-PEEK ply with five passes of graphene thin film

same as the silicon wafer as the methodology employed to synthesise the film was exactly the same.

The chemical quality of the spray-deposited graphene thin films was assessed using Raman spectroscopy and the collected spectra are shown in Fig. 4c and d. The G peaks on both CF-PEEK (Fig. 4c) and Si (Fig. 4d) can be fit with one Lorentzian curve and are associated with the frequency of aromatic carbon rings stretching at 1580 $\mathrm{cm}^{-1}$ [45]. The D peak evident on both CF-PEEK and Si samples was fitted with a single Lorentzian at 1350 $\mathrm{cm}^{-1}$; the D peak is activated when defects are present in the graphene due to elastic scattering of charge carriers which only occurs when armchair edges are present $[46,47]$. The presence of D' band at $1620 \mathrm{~cm}^{-1}$ with an $\mathrm{I}_{\mathrm{D}} / \mathrm{I}_{\mathrm{D}^{\prime}}=\sim 2.9$ reinforces the prominence of edge defects [48]. The D and D' peaks only occur when there is some level of disorder present in the graphene structure [46]: Disorder in graphene can arise due to corrugations (e.g. ripples, wrinkles), topological defects (e.g. dislocations and grain boundaries), and atomic vacancies or adatoms (i.e. missing carbons, extra carbons, or carbon substitutions in the structure) [49]. The $\mathrm{I}_{\mathrm{D}} / \mathrm{I}_{\mathrm{G}}$ intensity ratio increases with disorder and correlates with reduced charge carrier mobility [50]; the $\mathrm{I}_{\mathrm{D}} / \mathrm{I}_{\mathrm{G}}$ ratio of the thin film in this work was equal to $\sim 0.4$, typical for ultrasonic exfoliation synthesis $[46,51,52]$. This $\mathrm{I}_{\mathrm{D}} / \mathrm{I}_{\mathrm{G}}$ intensity ratio is also inversely proportional to crystallite size, calculated to be $11 \mathrm{~nm}$ in this work [53]. For context, the $\mathrm{I}_{\mathrm{D}} / \mathrm{I}_{\mathrm{G}}$ ratio is $\sim 0$ for pristine monolayer graphene and as high 1.31 for graphite [54]. The analysis of the D and G peaks in the spray-deposited graphene thin film are indicative of nanocrystalline carbon with the presence of edge defects $[44,46]$.

The 2D peaks represent valance $(\pi)$ and conduction $\left(\pi^{*}\right)$ bands where single layer graphene (SLG) can be fitted using a single Lorentzian peak [55]. In bilayer and few-layer graphene ( $<5$ layers), electronic interactions between the layers cause the $\pi$ and $\pi^{*}$ bands to split into four phonons which requires four Lorentzian bands to fit the 2D peak [56]. Four bands appeared at 2682, 2704, 2722, and $2739 \mathrm{~cm}^{-1}$ in the CF-PEEK (Fig. 4f) and 2691, 2717, 2736, and $2668 \mathrm{~cm}^{-1}$ in the Si sample (Fig. 4e). The intensity ratio of $G$ to $2 \mathrm{D}\left(\mathrm{I}_{\mathrm{G}} / \mathrm{I}_{2 \mathrm{D}}\right)$ for CF-PEEK and $\mathrm{Si}$ are 2.85 and 3.0, respectively, closer to the intensity ratio of graphite observed in literature but may be due to re-aggregation of the graphene during film formation [57]. The full width at half maximum of the $2 \mathrm{D}$ peak is $\sim 77 \mathrm{~cm}^{-1}$ in CF-PEEK and $\sim 73 \mathrm{~cm}^{-1}$ in Si which correlates to five or more layered graphene, but the centres of the $2 \mathrm{D}$ peaks are $2703 \mathrm{~cm}^{-1}$ which is indicative of 4layer graphene [55]. The shift of the $2 \mathrm{D}$ peak centre to a wavenumber of $2655 \mathrm{~cm}^{-1}$ [58] may be the result of substrate doping effects [59]. Collectively, the Raman spectroscopy analysis above indicates that the spraydeposited thin films are characteristic of 4-layer multilayer graphene [60]. The electronic structure of graphene is highly coupled to the number of layers and with 5 or fewer layers the properties of the nanomaterial begin to tend towards the theoretical properties intrinsic to monolayer graphene. The conducted Raman analysis indicates that these spray-deposited graphene thin films are well-suited to functionalising carbon fibre composites [56].

Electrical property enhancement using conductive nanomaterial addition requires achievement of a critical loading into the polymer matrix to result in a steep increase in conductivity of the bulk material referred to as the percolation threshold [61]. Dispersion and agglomeration of graphene nanofiller can strongly impact the measured electrical conductivity, where imperfections 


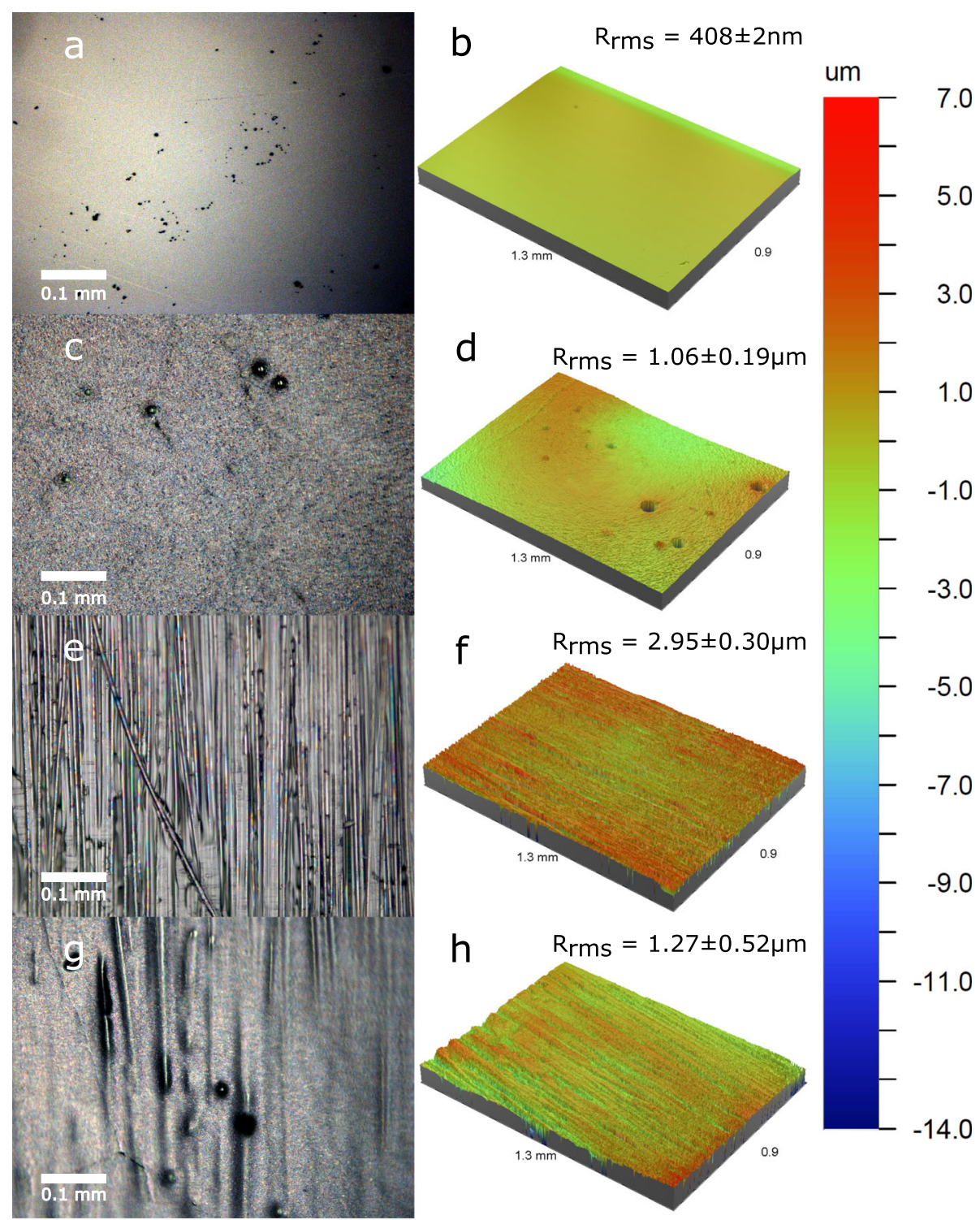

Fig. 3 Control substrate of highly boron doped Si wafer (a) optically imaged and (b) surface mapped using WLI. Graphene thin film deposited onto highly boron doped Si wafer substrate (c) optically imaged and the respective (d) WLI surface map. (e) Optical image of CF-PEEK control substrate and (f) WLI map and the addition of the (g) thin film onto CF-PEEK optically imaged and (h) WLI surface mapped

and defects at the graphene-polymer interface and electron tunnelling from one nanofiller to another are also important considerations [62]. After reaching the percolation threshold, the overall conductivity of the modified composite is generally dominated by the intrinsic electrical properties of the nanofiller and polymer matrix [62].

The 4-point probe measurements were conducted on the graphene suspension puck resulting in an average sheet conductivity of $2.6 \mathrm{Scm}^{-1}$. Through thickness values were measured using two point probe methods yielding conductivity of $0.010 \pm 3.7 \times 10^{-4} \mathrm{Scm}^{-1}$. The measured value is comparable to $\mathrm{Li}$ et al. [36] who reported a value of $1.32 \mathrm{Scm}^{-1}$ after spraying GNP/CNT hybrid coating onto CF-epoxy prepreg surfaces. Spray coated graphene nanoplatelets (GNP) onto CF achieved $52.2 \mathrm{Scm}^{-1}$ conductivity [63] while filtered and rolled graphene oxide thin films reported conductivities as high as $1800 \mathrm{Scm}^{-1}$ [33].

Cross sectional samples were inspected for the presence of graphene within the interlayer region of consolidated CF-PEEK parts (Fig. 5). Pocket voids are present within the $0^{\circ}$ fibre layer and interlayer regions in the CF-PEEK graphene enhanced sample (Fig. 5a). Comparatively smaller and longer void structures run through the $0^{\circ}$ ply and interlayer region in the CF-PEEK control sample depicted in Fig. 5b. The voids present in 

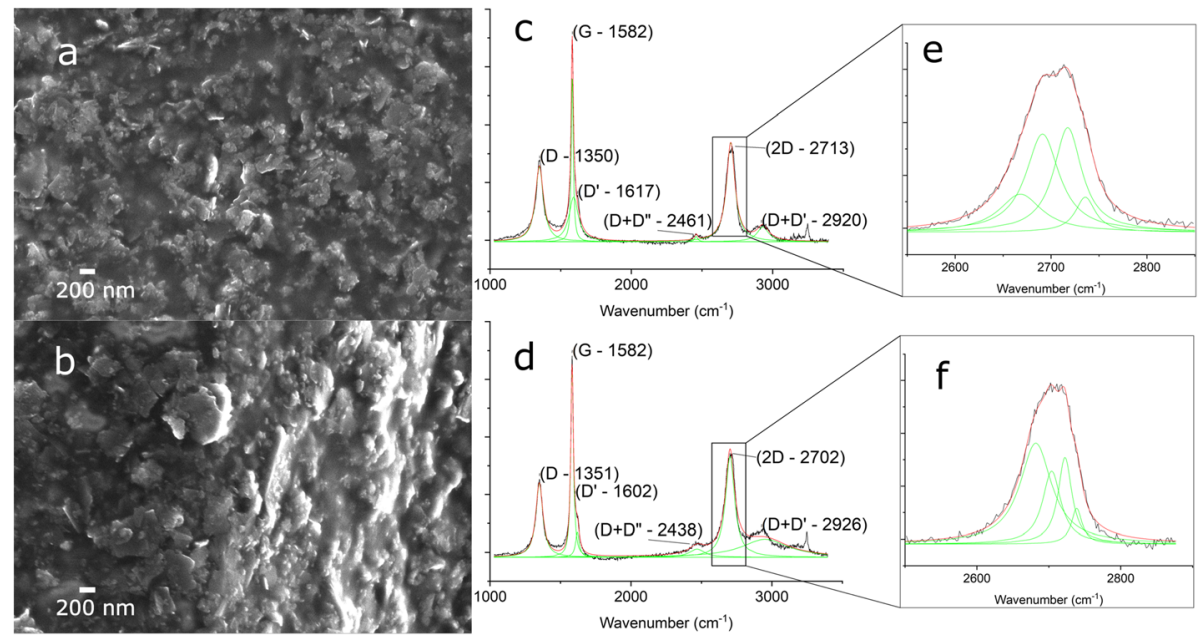

Fig. 4 SEM images of untreated graphene thin film deposited onto (a) Si and (b) CF-PEEK substrate. Raman spectra of graphene thin film on (c) Si substrate and (d) CF-PEEK substrate with respective four Lotenzian fits to the 2D peak for (e) Si and (f) CF-PEEK

the interlayer region may be due to a combination of hot press consolidation manufacturing combined with graphene thin film behaviour at elevated temperatures.

SEM images of the interlayer region of graphene enhanced CF-PEEK composites shows the presence of a graphene interlayer approximately $10 \mu \mathrm{m}$ thick (Fig. 5d) compared to the control (Fig. 5b). The graphene remains in the interlayer region after consolidation and is visible between the $0^{\circ}$ and $90^{\circ}$ plies in Fig. $5 \mathrm{~d}$. The Raman spectra for the interlayer region in Fig. 5e confirms the presence of graphene in the composite after consolidation. Figure $5 \mathrm{f}$ shows the spectral acquisition of the graphene interlayer region within the PEEK matrix where increased noise in the measurement is present due to PEEK polymer fluorescence emission [64].

The C-AFM measurements were taken of the resin embedded control and CF-PEEK graphene enhanced samples to understand the nanoscale electrical conductivity characteristics of the interlayer region (Fig. 6). The measurements reveal height differences in the fibre topographies compared to the matrix due to hardness property differences during polishing (Fig. 6a, b). AFM measurements were used to identify features and to ensure the interlayer region was being mapped during C-AFM measurements.

Figure $6 \mathrm{c}$ mapped the electrical conductivity of the same region as Fig. $6 \mathrm{~b}$ and demonstrates the ability of carbon fibres in both the $0^{\circ}$ and $90^{\circ}$ directions to conduct current on the nanoamp scale. The PEEK matrix interlayer region was completely non-conductive, as expected due to PEEK's insulating electrical properties $\left(3.745 \times 10^{-18} \mathrm{~S} / \mathrm{cm}[13]\right)$. The $0^{\circ}$ fibre edges, interlayer region, and $90^{\circ}$ fibre cross section of the control had optical density measurements of 25,1 , and 13 measured corresponding to $1,0.1,0.5 \mathrm{nA}$ respectively. In comparison, the graphene enhanced sample had higher optical

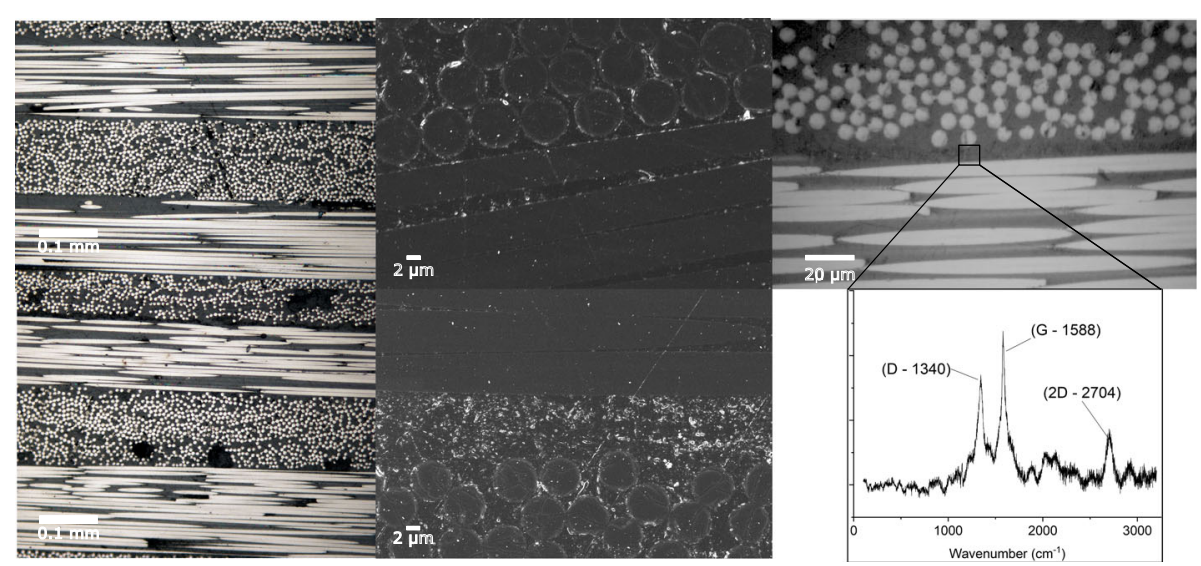

Fig. 5 Control consolidated CF-PEEK cross sectional (a) optical and (b) SEM image. Graphene enhanced consolidated cross-section (c) optical and (d) SEM image. (e) Raman scan of CF-PEEK with graphene in the interlayer region and (f) respective graphene spectra 

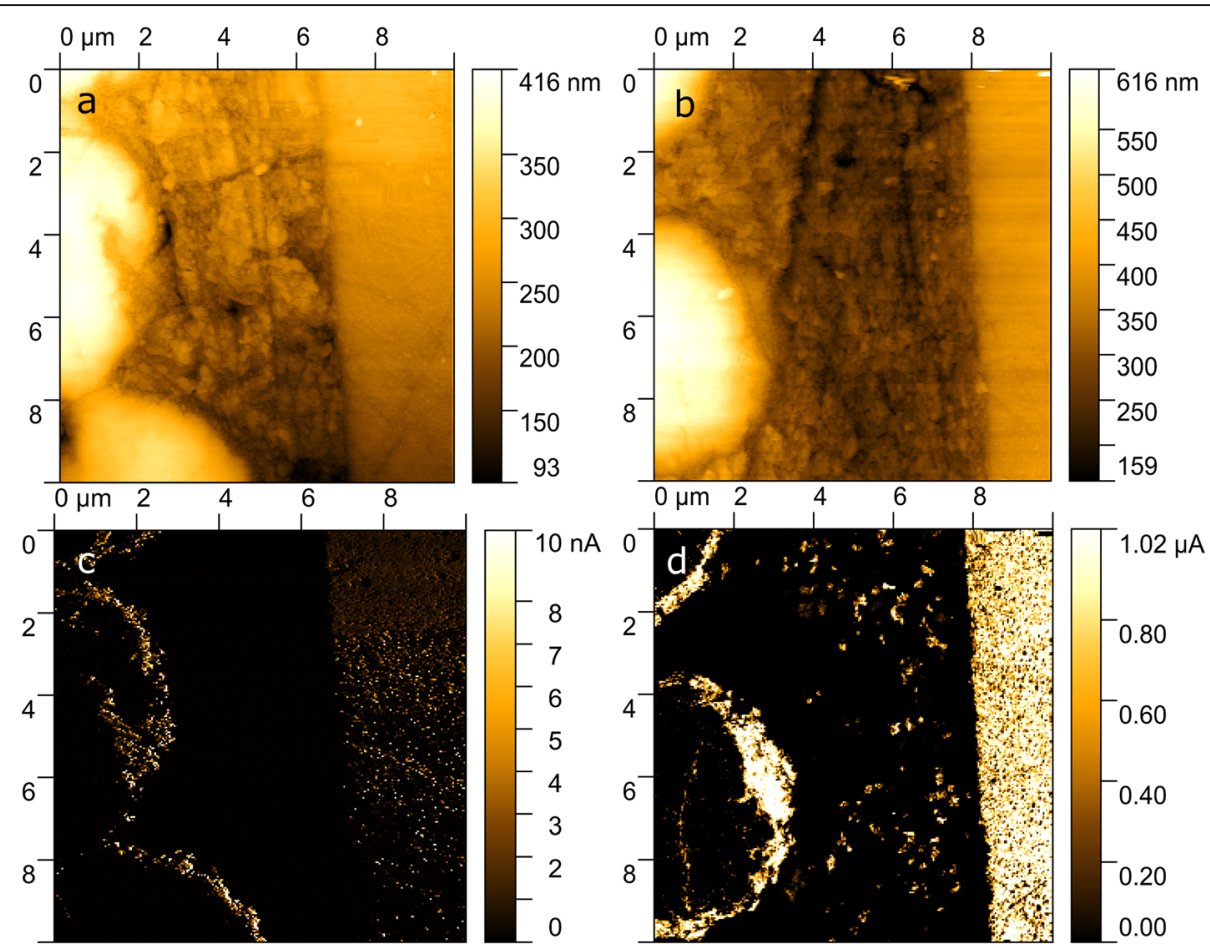

Fig. 6 AFM surface map of (a) CF-PEEK control and (b) graphene enhanced interlayer region. Conductivity maps (from left to right) of $0^{\circ}$ fibres, interlayer region and $90^{\circ}$ fibre measured on (c) control and (d) graphene enhanced samples

density measurements of 79,9 and 188 corresponding to conductivity values of $0.32,0.04$, and $0.75 \mu \mathrm{A}$ at the $0^{\circ}$ fibre edges, interlayer region, and $90^{\circ}$ fibre cross section respectively. Figure $6 \mathrm{~d}$ shows greater concentrations of electrical networks, measured via current flow from the C-AFM tip through the sample and into the sample base, at the edges of the $0^{\circ}$ carbon fibre and across the whole $90^{\circ}$ fibre. Additionally, patches of conductive regions are captured in the interlayer region with current measurements reaching microamps in the graphene enhanced sample. The interlayer conductive domains in Fig. $6 \mathrm{~d}$ were $328 \pm 9 \mathrm{~nm}$, which is consistent with the size of individual graphene flakes seen in the SEM images of the spray-deposited thin films (Fig. 4a); this suggests that graphene nanoparticles are well-dispersed in the interlaminar regions.

These C-AFM measurements are 2D representations of 3D data as conductive networks can only be captured when current flows to the preamplifier due to an applied potential difference between the sample holder and tip [65]. However, the presence of interconnected or adjacent conductive domains aided by graphene additives to form physical connections or quantum tunnelling effects between fibres through the matrix demonstrate the achievement of the percolation threshold [66].

The electrical conductivity of the CF-PEEK composites was enhanced via interlayer additions of graphene thin films (Fig. 7). In plane electrical conductivity of the graphene enhanced sample was recorded to be $0.008 \pm$ $0.002 \mathrm{Scm}^{-1}, 11$ times higher than the control sample at $(6.76 \pm 3.77) \times 10^{-4} \mathrm{Scm}^{-1}$. Slight improvement in the through thickness $(\mathrm{Z})$ directions of the cross-sectional composites was achieved with a $67.5 \%$ increase from $0.001 \pm 2.39 \times 10^{-5} \mathrm{Scm}^{-1}$ to $0.004 \pm 7.17 \times 10^{-4}$ $\mathrm{Scm}^{-1}$. Electrical conductivity measurements were not dominated by the conductivity of PEEK or carbon fibres $\left(500 \mathrm{Scm}^{-1}[67,68]\right)$ as measurements do not tend towards either value, which suggests that the inclusion of graphene in the interlayer has successfully modified the electrical properties of the composite rather than simply connecting carbon fibres. Kamiyama et al. [69] reported neat CF-PEEK longitudinal, transverse and through thickness conductivity values of $31.2 \mathrm{Scm}^{-1}, 0.485$ $\mathrm{Scm}^{-1}$, and $1.51 \times 10^{-2} \mathrm{Scm}^{-1}$, respectively. Use of conductive domains through thickness previously measured in C-AFM have resulted in bulk electrical property changes aligning with percolation threshold theory [66].

\section{Conclusion}

The aerosolisation of aqueous graphene suspensions was able to generate smooth thin films on both silicon wafers (RMS roughness of $1.06 \mu \mathrm{m}$ ) and CF-PEEK prepreg tapes (RMS roughness of $1.27 \mu \mathrm{m}$ ). Chemical characterisation via Raman spectroscopy is indicative of 4-layer 


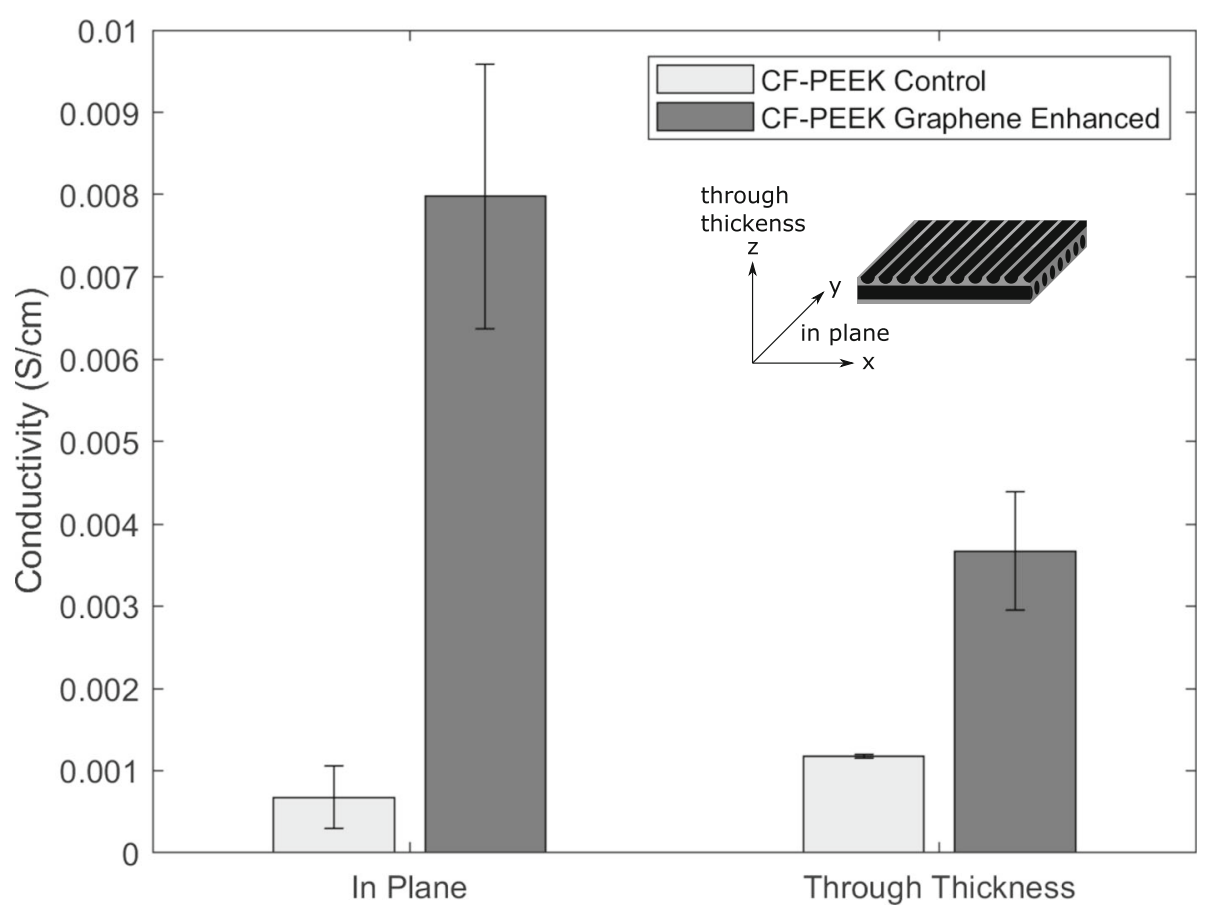

Fig. 7 Two-point probe conductivity measurements of consolidated CF-PEEK control and graphene enhanced samples. In plane measurements improved from $6.7 \times 10^{-4} \pm 3.7 \times 10^{-4} \mathrm{Scm}^{-1}$ to $0.008 \pm 0.0016 \mathrm{Scm}^{-1}$ and through thickness measurements improved from $0.0012 \pm 2.4 \times 10^{-5}$ $\mathrm{Scm}^{-1}$ to $0.0037 \pm 7.2 \times 10^{-4} \mathrm{Scm}^{-1}$. Error bars represent $95 \%$ confidence interval of the mean

multilayer graphene in the spray-deposited thin films. These high-quality graphene thin films were successfully incorporated into the interlayer regions of hot press consolidated CF-PEEK parts. The presence of graphene post-consolidation was confirmed with electron microscopy and Raman spectroscopy while the nanoconductivity of the interlayer region was measured directly using conductive AFM. Bulk electrical conductivity enhancement was achieved in both in plane $(\sim 1100 \%$ enhancement) and through thickness (67.5\% enhancement) directions of the graphene enhanced thermoplastic composite. This work demonstrates scalable nanomaterial functionalisation of CF-PEEK composites via the aerosolisation of graphene nanosuspensions. Future investigations into the effects of varying graphene content in the interlayer regions on thermal, electrical, and mechanical properties, specifically interlaminar shear strength, will be explored in greater detail.

\section{Abbreviations}

CFRP: Carbon Fibre Reinforced Plastics; ATP: Automated Tape Placement; PEEK: Polyether ether keytone; LPE: Liquid Phase Exfoliation; C-

AFM: Conductive-Atomic Force Microscopy; SE: Secondary Electron; WLI: White Light Interferometry; SEM: Scanning Electron Microscopy; VSI: Vertical Scanning Interferometry; GO: Graphene Oxide; CNT: Carbon Nanotube; GNP: Graphene Nanoplatelet; SLG: Single Layer Graphene

\section{Acknowledgements}

The authors acknowledge the scientific and technical assistance, of the Australian Microscopy \& Microanalysis Research Facility at the Centre of Advanced Microscopy; and the support of ANFF ACT Node (ANFF @ ANU) in carrying out this research. The authors also acknowledge FlexeGRAPH for supplying the graphene suspension and J. Bradby for providing the facilities for Raman spectroscopy measurements.

\section{Authors' contributions}

C. Leow, P. Kreider, P. Compston conceived the work; C. Leow drafted the work; C. Leow, P. Kreider, C. Notthoff conducted experiments, C. Leow analysed and visualised the data; P. Kreider, P. Compston, P. Kluth, A. Tricoli, C. Notthoff reviewed and edited the article; P. Compston, P. Kreider provided supervision; P. Compston acquired funding and provided project administration. The authors read and approved the final manuscript.

\section{Funding}

This project was conducted within the ARC Training Centre for Automated Manufacture of Advanced Composites (IC160100040), supported by the Commonwealth of Australia under the Australian Research Council's Industrial Transformation Research Program.

\section{Availability of data and materials}

All data generated or analysed during this study are included in this published article.

\section{Competing interests}

The authors declare that they have no competing interests.

\section{Author details}

${ }^{1}$ ARC Training Centre for Automated Manufacture of Advanced Composites, Research School of Electrical, Energy and Materials Engineering, Australian National University, Canberra, ACT 2601, Australia. ${ }^{2}$ Department of Electronic Materials Engineering, Research School of Physics, Australian National University, Canberra, ACT 2601, Australia. ${ }^{3}$ Nanotechnology Research Laboratory, College of Engineering and Computer Science, The Australian National University, Canberra, ACT 2601, Australia. 
Received: 3 November 2020 Accepted: 22 December 2020 Published online: 08 January 2021

\section{References}

1. T. Hu, X. Yu, Lightning Performance of Copper-Mesh Clad Composite Panels : Test and Simulation (2019)

2. K.A. Imran, K.N. Shivakumar, Graphene-modified carbon/epoxy Nanocomposites: Electrical, thermal and mechanical properties. J. Thermoplast. Compos. Mater. 53, 93 (2019)

3. K. Krushnamurty, M. Rini, I. Srikanth, P. Ghosal, A.P. Das, M. Deepa, C. Subrahmanyam, Conducting polymer coated Graphene oxide reinforced Cepoxy composites for enhanced electrical conduction. Compos. Part A Appl. Sci. Manuf. 80, 237 (2016)

4. D.M. Delozier, K.A. Watson, J.G. Smith, J.W. Connell, Preparation and characterization of space durable polymer Nanocomposite films. Compos. Sci. Technol. 65, 749 (2005)

5. J. Joseph, P.R. Munda, D.A. John, A.M. Sidpara, J. Paul, Graphene and CNT filled hybrid thermoplastic composites for enhanced EMI shielding effectiveness. Mater. Res. Express 6, 085617 (2019)

6. N. Yamamoto, R. Guzman de Villoria, B.L. Wardle, Electrical and thermal property enhancement of fiber-reinforced polymer laminate composites through controlled implementation of multi-walled carbon nanotubes. Compos. Sci. Technol. 72, 2009 (2012)

7. J. Wu, J. Chen, Y. Zhao, W. Liu, W. Zhang, Effect of electrophoretic condition on the electromagnetic interference shielding performance of reduced Graphene oxide-carbon fiber/epoxy resin composites. Compos. Part B Eng. 105, 167 (2016)

8. C. González, J.J. Vilatela, J.M. Molina-Aldareguía, C.S. Lopes, J. LLorca, Structural composites for multifunctional applications: Current challenges and future trends. Prog. Mater. Sci. 89, pp. 194-251

9. U. Szeluga, B. Kumanek, B. Trzebicka, Synergy in hybrid polymer/ Nanocarbon composites. A review. Compos. Part A Appl. Sci. Manuf. 73, 204 (2015)

10. K.K. Sairajan, G.S. Aglietti, K.M. Mani, A review of multifunctional structure technology for aerospace applications. Acta Astronaut. 120, 30 (2016)

11. L. Siebert, T. Schaller, F. Schütt, S. Kaps, J. Carstensen, S. Shree, J. Bahr, Y.K. Mishra, H.H. Sievers, R. Adelung, Perfect polymer interlocking by spherical particles: Capillary force shapes hierarchical composite undercuts. Nanoscale Horizons 4, 947 (2019)

12. A.M. Díez-Pascual, M. Naffakh, M.A. Gómez, C. Marco, G. Ellis, M.T. Martínez, A. Ansón, J.M. González-Domínguez, Y. Martínez-Rubi, B. Simard, Development and characterization of PEEK/carbon nanotube composites. Carbon N Y 47, 3079 (2009)

13. J.A. King, J.M. Tomasi, D.R. Klimek-McDonald, I. Miskioglu, G.M. Odegard, T.R. King, J.W. Sutherland, Effects of carbon fillers on the conductivity and tensile properties of Polyetheretherketone composites. Polym. Compos. 39, E807 (2018)

14. O. Meincke, D. Kaempfer, H. Weickmann, C. Friedrich, M. Vathauer, H. Warth, Mechanical properties and electrical conductivity of carbon-nanotube filled Polyamide- 6 and its blends with acrylonitrile/butadiene/styrene. Polymer (Guildf) 45(739), 739-748 (2004)

15. H. Yang, J. Gong, X. Wen, J. Xue, Q. Chen, Z. Jiang, N. Tian, T. Tang, Effect of carbon black on improving thermal stability, flame Retardancy and electrical conductivity of polypropylene/carbon fiber composites. Compos. Sci. Technol. 113, 31 (2015)

16. V.P. Veedu, A. Cao, X. Li, K. Ma, C. Soldano, S. Kar, P.M. Ajayan, M.N. GhasemiNejhad, Multifunctional composites using reinforced laminae with carbonnanotube forests. Nat. Mater. 5, 457 (2006)

17. E. Bekyarova, E.T. Thostenson, A. Yu, H. Kim, J. Gao, J. Tang, H.T. Hahn, T.W. Chou, M.E. Itkis, R.C. Haddon, Multiscale carbon nanotube-carbon fiber reinforcement for advanced epoxy composites. Langmuir 23, 3970 (2007)

18. Y. Li, H. Zhang, Z. Huang, E. Bilotti, T. Peijs, Graphite Nanoplatelet modified epoxy resin for carbon fibre reinforced plastics with enhanced properties. J. Nanomater. 2017, 1-10 (2017)

19. Y. Lan, H. Liu, X. Cao, S. Zhao, K. Dai, X. Yan, G. Zheng, C. Liu, C. Shen, Z. Guo, Electrically conductive thermoplastic polyurethane/polypropylene Nanocomposites with selectively distributed Graphene. Polymer (Guildf) 97(11), 11-19 (2016)

20. W. Lee, J.U. Lee, H.J. Cha, J.H. Byun, Partially reduced Graphene oxide as a multi-functional sizing agent for carbon fiber composites by electrophoretic deposition. RSC Adv. 3, 25609 (2013)
21. L.Q. Cortes, S. Racagel, A. Lonjon, E. Dantras, C. Lacabanne, Electrically conductive carbon fiber / PEKK / silver nanowires multifunctional composites. Compos. Sci. Technol. 137, 159 (2016)

22. J. Li, P.S. Wong, J.K. Kim, Hybrid Nanocomposites containing carbon nanotubes and graphite Nanoplatelets. Mater. Sci. Eng. A 483-484, 660 (2008)

23. Y.J. Kwon, Y. Kim, H. Jeon, S. Cho, W. Lee, J.U. Lee, Graphene/carbon nanotube hybrid as a multi-functional interfacial reinforcement for carbon fiber-reinforced composites. Compos. Part B Eng. 122, 23 (2017)

24. C. Lee, X. Wei, J.W. Kysar, J. Hone, Measurement of the elastic properties and intrinsic strength of monolayer Graphene. Science (80- ) 321, 385 (2008)

25. Y. Zhu, S. Murali, W. Cai, X. Li, J.W. Suk, J.R. Potts, R.S. Ruoff, Graphene and Graphene oxide: Synthesis, properties, and applications. Adv. Mater. 22, 3906 (2010)

26. A.A. Balandin, S. Ghosh, W. Bao, I. Calizo, D. Teweldebrhan, F. Miao, C.N. Lau, Superior thermal conductivity of single-layer Graphene. Nano. Lett. 8, 902 (2008)

27. R. Raccichini, A. Varzi, S. Passerini, B. Scrosati, The role of Graphene for electrochemical energy storage. Nat. Mater. 14, 271 (2015)

28. E. Kandare, A.A. Khatibi, S. Yoo, R. Wang, J. Ma, P. Olivier, N. Gleizes, C.H. Wang, Improving the through-thickness thermal and electrical conductivity of carbon fibre/epoxy laminates by exploiting synergy between Graphene and silver Nano-inclusions. Compos. Part A Appl. Sci. Manuf. 69, 72 (2015)

29. S.M. Notley, Highly concentrated aqueous suspensions of Graphene through ultrasonic exfoliation with continuous surfactant addition. Langmuir 28, 14110 (2012)

30. U. Khan, A. O'Neill, M. Lotya, S. De, J.N. Coleman, High-concentration solvent exfoliation of Graphene. Small 6, 864 (2010)

31. F. An, C. Lu, Y. Li, J. Guo, X. Lu, H. Lu, S. He, Y. Yang, Preparation and characterization of carbon nanotube-hybridized carbon fiber to reinforce epoxy composite. Mater. Des. 33, 197 (2012)

32. F. Hussain, M. Hojjati, M. Okamoto, R.E. Gorga, Review article: Polymer-matrix Nanocomposites, processing, manufacturing, and application: An overview. J. Thermoplast. Compos. Mater. 40, 1511 (2006)

33. V. Kumar, S. Sharma, A. Pathak, B.P. Singh, S.R. Dhakate, T. Yokozeki, T. Okada, T. Ogasawara, Interleaved MWCNT Buckypaper between CFRP laminates to improve through-thickness electrical conductivity and reducing lightning strike damage. Compos. Struct. 210, 581 (2019)

34. S.S.A. Kumar, M.N. Uddin, M.M. Rahman, R. Asmatulu, Introducing Graphene thin films into carbon fiber composite structures for lightning strike protection. Polym. Compos. 40, E517 (2019)

35. H. Zhang, Y. Liu, M. Kuwata, E. Bilotti, T. Peijs, Improved fracture toughness and integrated damage sensing capability by spray coated CNTs on carbon fibre Prepreg. Compos. Part A Appl. Sci. Manuf. 70, 102 (2015)

36. Y. Li, H. Zhang, Y. Liu, H. Wang, Z. Huang, T. Peijs, E. Bilotti, Synergistic effects of spray-coated hybrid carbon nanoparticles for enhanced electrical and thermal surface conductivity of CFRP laminates. Compos. Part A Appl. Sci. Manuf. 105, 9 (2018)

37. F.N. Cogswell, F. Neil, Platen Pressing of Carbon Fibre/PEEK Laminates, in Thermoplastic Aromatic Polymer Composites Materials (Butterworth Heinemann, Oxford, 1992), p. 249

38. M. Lotya, P.J. King, U. Khan, S. De, J.N. Coleman, High-concentration, surfactant-stabilized Graphene dispersions. ACS Nano. 4, 3155 (2010)

39. V. Chabot, B. Kim, B. Sloper, C. Tzoganakis, A. Yu, High yield production and purification of few layer Graphene by gum Arabic assisted physical sonication. Sci. Rep. 3, 1378 (2013)

40. M. Lotya, Y. Hernandez, P.J. King, R.J. Smith, V. Nicolosi, L.S. Karlsson, F.M. Blighe, S. De, W. Zhiming, I.T. McGovern, G.S. Duesberg, J.N. Coleman, Liquid phase production of Graphene by exfoliation of graphite in surfactant/water solutions. J. Am. Chem. Soc. 131, 3611 (2009)

41. A.S. Wajid, S. Das, F. Irin, H.S.T. Ahmed, J.L. Shelburne, D. Parviz, R.J. Fullerton, A.F. Jankowski, R.C. Hedden, M.J. Green, Polymer-stabilized Graphene dispersions at high concentrations in organic solvents for composite production. Carbon N Y 50, 526 (2012)

42. A.F. Stalder, T. Melchior, M. Müller, D. Sage, T. Blu, M. Unser, Low-bond axisymmetric drop shape analysis for surface tension and contact angle measurements of sessile drops. Colloids Surfaces A Physicochem. Eng. Asp. 364, 72 (2010)

43. Signatone, Signatone Four Point Probe Part Numbers SP4 (2018)

44. M.M. Lucchese, F. Stavale, E.H.M. Ferreira, C. Vilani, M.V.O. Moutinho, R.B. Capaz, C.A. Achete, A. Jorio, Quantifying ion-induced defects and Raman relaxation length in Graphene. Carbon N Y 48, 1592 (2010) 
45. M.B. Vázquez-Santos, E. Geissler, K. László, J.N. Rouzaud, A. Martínez-Alonso, J.M.D. Tascón, Comparative XRD, Raman, and TEM study on graphitization of PBO-derived carbon fibers. J. Phys. Chem. C 116, 257 (2012)

46. I. Childres, L.A. Jauregui, W. Park, H. Caoa, Y.P. Chena, in New Developments in Photon and Materials Research. Raman spectroscopy of Graphene and related materials (2013), pp. 403-418

47. M. Acik, Y.J. Chabal, Nature of Graphene edges: A review. Jpn. J. Appl. Phys. 50, 070101 (2011)

48. R. Narayan, J. Lim, T. Jeon, D.J. Li, S.O. Kim, Perylene Tetracarboxylate surfactant assisted liquid phase exfoliation of graphite into Graphene Nanosheets with facile re-Dispersibility in aqueous/organic polar solvents. Carbon N Y 119, 555 (2017)

49. G. Yang, L. Li, W.B. Lee, M.C. Ng, Structure of Graphene and its disorders: A review. Sci. Technol. Adv. Mater. 19, 613 (2018)

50. B. Ma, R.D. Rodriguez, A. Ruban, S. Pavlov, E. Sheremet, The correlation between electrical conductivity and second-order Raman modes of laserreduced Graphene oxide. Phys. Chem. Chem. Phys. 21, 10125 (2019)

51. H. Lu, Y. Yao, W.M. Huang, D. Hui, Noncovalently functionalized carbon fiber by grafted self-assembled Graphene oxide and the synergistic effect on polymeric shape memory Nanocomposites. Compos. Part B Eng. 67, 290 (2014)

52. N.U. Saidin, K.K. Ying, C.T. Foo, R. Hazan, M.E. Mahmoud, Direct exfoliation of graphite and its Raman spectroscopic study. Mater. Today. Proc. 7, 798 (2019)

53. A.C. Ferrari, D.M. Basko, Raman spectroscopy as a versatile tool for studying the properties of Graphene. Nat. Nanotechnol. 8, 235 (2013)

54. A.A. Dubale, W.-N. Su, B. Andebet, G. Tamirat, C.-J. Pan, B.A. Aragaw, H.-M. Chen, C.-H. Chen, B.-J. Hwang, The Synergetic Effect of Graphene on Cu 20 Nanowire Arrays as a Highly Efficient Hydrogen Evolution Photocathode in Water Splitting + (2014)

55. Y. Hao, Y. Wang, L. Wang, Z. Ni, Z. Wang, R. Wang, C.K. Koo, Z. Shen, J.T.L. Thong, Probing layer number and stacking order of few-layer Graphene by Raman spectroscopy. Small 6, 195 (2010)

56. A.C. Ferrari, J.C. Meyer, V. Scardaci, C. Casiraghi, M. Lazzeri, F. Mauri, S. Piscanec, D. Jiang, K.S. Novoselov, S. Roth, A.K. Geim, Raman Spectrum of Graphene and Graphene layers. Phys. Rev. Lett. 97, 1 (2006)

57. S. Gayathri, P. Jayabal, M. Kottaisamy, V. Ramakrishnan, Synthesis of few layer Graphene by direct exfoliation of graphite and a Raman spectroscopic study. AlP Adv. 4, 027116 (2014)

58. A.C. Ferrari, Raman spectroscopy of Graphene and graphite: Disorder, electron-phonon coupling, doping and nonadiabatic effects. Solid State Commun. 143, 47 (2007)

59. H. Bukowska, F. Meinerzhagen, S. Akcöltekin, O. Ochedowski, M. Neubert, V. Buck, M. Schleberger, Raman spectra of Graphene exfoliated on insulating crystalline substrates. New J. Phys. 13, 063018 (2011)

60. Y. Liu, Z. Liu, W.S. Lew, Q.J. Wang, Temperature dependence of the electrical transport properties in few-layer Graphene interconnects. Nanoscale Res. Lett. 8, 1 (2013)

61. N.A. Mohd Radzuan, A.B. Sulong, J. Sahari, A review of electrical conductivity models for conductive polymer composite. Int. J. Hydrogen Energy 42, 9262 (2017)

62. Y. Wang, J.W. Shan, G.J. Weng, Percolation threshold and electrical conductivity of Graphene-based Nanocomposites with filler agglomeration and interfacial tunneling. J. Appl. Phys. 118, 065101 (2015)

63. B. Zhang, V.R. Patlolla, D. Chiao, D.K. Kalla, H. Misak, R. Asmatulu, Galvanic corrosion of Al/cu meshes with carbon fibers and Graphene and ITO-based Nanocomposite coatings as alternative approaches for lightning strikes. Int. J. Adv. Manuf. Technol. 67, 1317 (2013)

64. D. Wei, S. Chen, Q. Liu, Review of fluorescence suppression techniques in Raman spectroscopy. Appl. Spectrosc. Rev. 50, 387 (2015)

65. G. Benstetter, A. Hofer, D. Liu, W. Frammelsberger, M. Lanza, in Conductive Atomic Force Microscopy: Applications in Nanomaterials, ed. by M. Lanza. Conductive atomic force microscopy (Wiley-VCH Verlag GmbH \& Co. KGaA, Weinheim, 2017)

66. R. Taherian, Experimental and analytical model for the electrical conductivity of polymer-based Nanocomposites. Compos. Sci. Technol. 123, 17 (2016)

67. I.C. Finegan, G.G. Tibbetts, Electrical conductivity of vapor-grown carbon fiber/thermoplastic composites. Mater. Res. Soc. 16, 1668 (2001)

68. W. Thongruang, R.J. Spontak, C.M. Balik, Correlated electrical conductivity and mechanical property analysis of high-density polyethylene filled with graphite and carbon fiber. Polymer (Guildf) 43(2279), 2279-2286 (2002)
69. S. Kamiyama, Y. Hirano, T. Okada, T. Ogasawara, Lightning strike damage behavior of carbon fiber reinforced epoxy, Bismaleimide, and Polyetheretherketone composites. Compos. Sci. Technol. 161, 107 (2018)

\section{Publisher's Note}

Springer Nature remains neutral with regard to jurisdictional claims in published maps and institutional affiliations.

\section{Submit your manuscript to a SpringerOpen ${ }^{\circ}$ journal and benefit from:}

- Convenient online submission

- Rigorous peer review

- Open access: articles freely available online

High visibility within the field

- Retaining the copyright to your article

Submit your next manuscript at $\boldsymbol{\nabla}$ springeropen.com 